\title{
0098 LOCAL AREA INCLUSIVE TRAUMA MANAGEMENT FOR ROAD SAFETY UDONTHANI MUNICIPALITY, THAILAND; 2003-2007
}

A Sethasathien, D Kommuangpuk* Correspondence: Udonthani Hospital, Udonthani Province 41000, Thailand

\subsection{6/ip.2010.029215.98}

Deaths from road traffic injury (RTI) have always been the top three of Thai. Mortality over 20 per 100000 . Udonthani municipality was also confronted with this problem. In 2003, dead from RTI was up to 53 cases. The most injured persons were male (69.9\%), with active age group and top vehicle type was motorcycle (78.3\%). The occupations were labours and students $(26.5 \%$ and $23.4 \%)$. But dead cases was decrease from 2003 to 2007 (52,39,21, 15 and 4 cases respectively) after inclusive trauma management was applied by the provincial road safety committee. That included Injury surveillance for monitoring, Prevention activities, Emergency Medical Service System, Mass casualty Preparedness and Critical Trauma Care. For prevention, we used $3 \mathrm{E}$ strategies (education in labours and student risk group; enforcement on helmet, seatbelt, drunk and speed control; engineering for reconstructing the black spot. From the registry we found that the risks factor in alcohol drunk drived injured, non-helmet and non-seatbelt were decrease year by year (alcohol drinking $=694,369,209,304$ and 150 cases; non-helmet $=1290,641,392,396$ and 294 cases; non-seatbelt $=$ $31,12,6,5$ and 4 cases respectively). For environmental management systems, trends of qualified first aid in four critical procedures including respiratory care, stop bleeding, splint and intravenous fluid were improved from $10 \%$ in 2003 to more than $80 \%$ in 2007 . For improvement of critical trauma care, we had decreased the percentage of dead case with Trauma and Injury Severity Score more than 0.75 in 5 years. 